\title{
A SITUAÇÃO DAS MULHERES NA ADMINISTRAÇÂO PÚBLICA BRASILEIRA DURANTE A PANDEMIA DO COVID-19
}

\author{
THE SITUATION OF WOMEN IN BRAZILIAN PUBLIC ADMINISTRATION \\ DURING THE COVID-19 PANDEMIC
}

Lucyléa Gonçalves França ${ }^{1}$

\begin{abstract}
Resumo: Este artigo investiga as políticas públicas brasileiras dirigidas a proteger o princípio de igualdade, sob a perspectiva de gênero. Utiliza como a metodologia jurídico-teórica pela via do método de investigação hipotéticodedutivo e empírico-científico. O texto trata das situações de conflitos que marcam a longa trajetória na luta pela concretização de direitos à igualdade das mulheres no contexto social e profissional no Brasil, e o enfrentamento da questão de gênero a partir da perspectiva da pandemia do COVID-19, com o propósito de examinar os efeitos de novas práticas, como o tele trabalho para as mulheres no período da emergência sanitária do primeiro semestre de 2020. O tema se impõe como de grande relevância considerando as diferenças sociais entre homens e mulheres sendo fruto da discriminação de gênero pela ausência de mecanismos legislativos ou de políticas públicas capazes de assegurar, de modo mais adequado, o ordenamento jurídico do Brasil ao cumprimento do direito de igualdade previsto na Constituição Brasileira de 1988.
\end{abstract}

Palavras-Chave: Administração pública; Gênero; Igualdade.

\begin{abstract}
This article investigates Brazilian public policies aimed at protecting the principle of equality, from a gender perspective. It uses as the legal-theoretical methodology through the hypothetical-deductive and empiricalscientific investigation method. The text deals with the conflict situations that mark the long trajectory in the struggle for the realization of women's equality rights in the social and professional context in Brazil, and the confrontation of the gender issue from the perspective of the COVID-19 pandemic, with the purpose of examining the effects of new practices, such as tele-work for women in the health emergency period of the first semester of 2020. The theme is of great relevance considering the social differences between men and women as a result of gender discrimination by absence of legislative mechanisms or public policies capable of ensuring, in a more adequate way, Brazil's legal system for the fulfillment of the right to equality provided for in the Brazilian Constitution of 1988.
\end{abstract}

Keywords: Public administration; Gender; Equality.

\section{Introdução}

A investigação e o debate sobre a igualdade e a equidade de gênero ${ }^{2}$, e seus impactos nas

\footnotetext{
${ }^{1}$ Doutora em Direito pela Universidade de Salamanca, Mestre em Direito pela Universidade Federal de Pernambuco. Professora do curso de Direito da Universidade Federal do Maranhão (Brasil) https://orcid.org/0000-0002-13645786.email: lucyfranca@gmail.com

${ }^{2}$ Existem inúmeras definições dadas por cada legislador, pela jurisprudência e inclusive diferentes autores que tratam o tema. Entre elas destacamos a defendida por SERRA CRISTÓBAL, R., La discriminación indirecta por razón de sexo. Discriminación versus diferenciación (especial referencia a La problemática de la mujer). Ridaura Martines, M. J. Aznar Gómez, M.J. (coord.) Tirant lo Blanch alternativa. Valencia. 2004. Pp. 367-368
} 
políticas públicas, dos países que adotam um modelo de Estado social e democrático de direito representam os resultados obtidos da ação positiva da Administração pública e seguem um ritmo próprio e variável de evolução em cada país ${ }^{3}$.

O marco jurídico, político e social aprimoram em geral conquistas e retrocessos nas questões de gênero ${ }^{4}$, perseguidos e originados dos esforços dos movimentos sociais de mulheres no cenário político, e dentro do jogo de poder em vários momentos históricos decisivos para o avanço para a igualdade.

O presente artigo está dividido em quatro capítulos incluindo a análise do panorama geral dos efeitos da pandemia do COVID 19 para as mulheres, iniciando com um breve discurso histórico sobre a igualdade de gênero, abordando a proteção jurídica quanto à igualdade de gênero no modelo constitucional brasileiro, e finalizando com a questão de gênero na pandemia do COVID-19.

Nos séculos XX e XXI a construção de políticas favorecedoras para as transformações dessas relações de gênero, no contexto das relações laborais, sustenta, historicamente, forças que, muitas vezes, respondem a uma espécie de contradiscurso retrogrado que visa minimizar os efeitos de experiências avançadas a nível constitucional. Por vezes, certos modelos de gestão debilitaram as possibilidades de efetivação de políticas de igualdade de oportunidades entre homens e mulheres.

A recente interpretação de igualdade formal, e material, de direitos no contexto do constitucionalismo brasileiro sinaliza que a assimilação do debate público do discurso de gênero tampouco é tão antiga em muitos países. Quando se questiona se existem grandes distinções entre a estrutura de poder e de organização da vida cotidiana em países que optam por ações que visam melhorar a situação de gênero e resposta é inegavelmente positiva.

Portanto, novas oportunidades para as mulheres surgem a partir da Constituição da República de 1988, com a exigência de concurso público para o desempenho de funções no executivo, no legislativo e no judiciário. A entrada em vigor do Estatuto dos servidores públicos federal (Lei ${ }^{\circ}$. 8.112/90) também augura o discurso de igualdade de gênero como conceito transverso e de fundo que encontram no ordenamento jurídico infraconstitucional sintonia com a

\footnotetext{
${ }^{3}$ Bustos adverte que a sociedade está todavia organizada de acordo com a norma masculina, assim que, garantir o reconhecimento de uma igualdade real e efetiva para a mulher não é tarefa fácil pois exige a eliminação de certas formas de discriminação e mais além, a concretização da não discriminação. In: GONZÀLEZ BUSTOS, M. Ángeles. Medidas Jurídico-administrativas para La protección de la mujer. Estudios multisciplinares de género. Revista Centro de ESTUDIO DE LA Mujer. N. 3. Aquilafuente. 99. Ediciones Universidad de Salamanca. 2006.Pp. 183-196.

${ }^{4}$ Para Martínez Quinteiro, mais que nunca as mulheres e homens no nosso século, especialmente nas sociedades democráticas, são assaltados por discursos de gênero contrapostos que se superpõem e que competem recebendo em certas ocasiões mensagens duais e contraditórias por discursos que, as vezes são oportunos o provocadores. Ver MARTİNEZ QUINTEIRO, M. Ester. Discuros y contradiscursos. Las relaciones de Género en el cine. In: Mujeres en la Historia,el arte y el cine: Discursos de Género, Variantes de contenidos y soportes de la Palabra al audiovisual. Aquilafuente. Ediciones Universidad Salamanca. 2011. Pp. 14
} 
matéria de igualdade de oportunidades, e na democratização e acessibilidade, ao maior número de postos de trabalho na administração pública no Brasil.

O discurso de gênero foi amoldado ao modelo de Administração pública brasileiro de modo indireto, ademais, muito pouco avançou a legislação brasileira quanto à melhora das questões de igualdades de oportunidades fora do âmbito do exercício das funções públicas, o que nos leva a crer que na atualidade o concurso público é um ou, melhor dizendo, o único instrumento básico e operativo à disposição da sociedade brasileira em favor de um plano estratégico de igualdade de oportunidades entre homens e mulheres, no desempenho, e na formação profissional.

Assim sendo, inegavelmente é no âmago do serviço público do Brasil que a igualdade de gênero alcança os maiores níveis, fazendo com que as discriminações históricas sejam minimizadas notavelmente.

Trinta anos depois da promulgação da Constituição da república do Brasil de 1988 o presente artigo propõe analisar a atuação feminina no setor público, empregador de grande importância no país, e, após alguns avanços se impõe refletir e debater sobre os efeitos da COVID 19 e as questões de gênero.

\section{Breve discurso histórico}

Como vimos essa dualidade material não é recente nem tampouco é amortizada por um conceito essencial de igualdade a nível constitucional. As situações de inferioridade são reflexos de um modo de exclusão na tomada de decisões no país, o que somente se resumem às políticas de erradicação da violência contra mulheres .A ménor participação e o desequilíbrio histórico entre mulheres e homens nascem da ausência da atuação do Estado em primar pelo estabelecimento de medidas efetivas de proteção, sobretudo para assegurar meios de conciliação da vida pessoal, familiar e laboral.

O direito ao voto feminino no Brasil ocorreu em 1932, depois de uma campanha que reunia mulheres profissionais, trabalhadoras, funcionárias públicas e enfermeiras, mas não trabalhadoras fabris. Essa vitória teve uma vida curta, pois em 1937 um golpe bania as eleições e excluía as mulheres da diplomacia e outros postos governamentais aos quais tinham sido admitidas recentemente .

\footnotetext{
${ }^{5}$ Existe uma tendencia a que as legislacoes centrem sua atencao em materia de igualdade no probemas de violencia de gênero. Neste sentido, PALOMAR OLDEMA, A. El principio de igualdad y La interdicción de la discriminación por razón de seco desde una perspectiva constitucional. In: El tratamiento de género en el ordenamiento español ( una visión multidisciplinar de la mujer en los distintos ámbitos sociales). Palomar Olmeda (Coord.) Tirant lo Blanch. Valencia. Pp. 78-89

${ }^{6}$ Hahner, June. 1981. A mulher brasileira e suas lutas sociais e políticas: 1850-1937. Ed. Brasiliense, São Paulo.
} 
A partir de 1938, com a exigência de um maior número de concursos, públicos e abertos, com testes anônimos, o serviço público federal registrou 8,8\% de mulheres. Em 1958 esse percentual alcançou $20,6 \%$ sendo para os cargos efetivos (26,4\% mulheres), e não efetivos $(15,9 \%)^{7}$.

São raras no Brasil as pesquisas de campo sobre as mulheres na administração pública. Entretanto, estudos demonstram que as crescente industrialização no país no século XXI influenciaram na expansão do ensino ${ }^{8}$.

Dados da Escola Nacional de Administração Pública (Enap) mostram que elas ainda são minoria na elite do serviço público. No Poder Executivo, mulheres representam $46 \%$ do total. No Judiciário, 9\%. E no Legislativo, 2\%, apenas.

No Executivo, 48\% das servidoras têm nível superior completo, enquanto que o percentual masculino formado fica em $43 \%$. As com pós-graduação chegam $5 \%$ ante $4 \%$ dos servidores; as com mestrado, $8 \%$ contra $7 \%$; e quando assunto é doutorado, os percentuais se assemelham $11 \%$ das funcionárias possuem a extensão ante $12 \%$ dos homens. Nos níveis que exigem menor conhecimento, a participação do sexo feminino é menor do que a do masculino: $4 \%$ tem ensino fundamental contra $8 \%$ dos homens; e $24 \%$ concluíram o ensino médio ante $26 \%$.

Outras circunstâncias como a menor participação da mulher nas instituições públicas é também observada no exercício de mandatos eletivos, o que consolida, historicamente, um sistema excludente baseada na distinção social entre homens e mulheres. Neste contexto, as mulheres não chegam a desfrutar de nenhuma garantia legal de flexibilidade com a redução da jornada laboral, seja com o reduzido horário laboral ou o aumento de período de licença maternidade. Entretanto, o maior impacto discriminatório ainda está na iniciativa privada, quando os vencimentos das mulheres são inferiores a dos varões, mesmo desempenhando atividades no mesmo posto de trabalho.

Em relação à remuneração no setor público, o percentual de mulheres em cargos com salários menores é equivalente a dos homens, mas cai no topo de carreira. Ambos os sexos têm participação de 3\% na faixa entre R \$ 1 mil e R \$ 3 mil. 9\% das mulheres ocupam vagas de R \$ 2 mil a R\$ 3 mil, contra $8 \%$ dos homens. Elas estão em maior número, $21 \%$ ante $17 \%$, quando a remuneração fica entre $\mathrm{R} \$ 3$ mil e $\mathrm{R}$ \$ 4,5 mil. Tem participação igual na faixa entre $\mathrm{R}$ \$ 6,5 mil e R \$ 8,5 mil, de $12 \%$. Entretanto, com o incremento dos cargos vinculados a maiores ganhos mensais a situação vai se invertendo: de R \$ 10,5 mil a R \$ 12,5 mil, elas são 5\% e eles, $6 \%$. No topo, com R\$

\footnotetext{
${ }^{7}$ Vieira da Cunha, Mario W. O sistema administrativo brasileiro 1930-1950. Centro Brasileiro de Pesquisas Educacionais. Rio de Janeiro.1963.pg. 963

8 BELTRÃO, Kaizô Iwakami; ALVES, José Eustáquio Diniz. A reversão do Hiato de Gênero na educação brasileira no século XX. Cadernos de Pesquisa, v. 39, n. 136, p. 125-156, jan./abr. 2009. Disponível em: $<$ http://publicacoes.fcc.org.br/ojs/index.php/cp/article/view/277>. Acesso em: 17 jan. 2019
} 
12,5 mil ou mais, elas despencam para $12 \%$ e eles saltam para $17 \%$.

Se a presença da mulher no mundo laboral sofreu uma sensível melhora nos últimos anos , esse fato não se deu em razão de políticas públicas de inclusão, mas sim, pela evolução da taxa de atividade feminina ter acompanhado o crescimento das cifras relativas à criação de mais postos de trabalho. Entretanto, essa realidade não equivale a novas medidas de caráter salarial e de geração de novos postos de trabalho e de chefias às mulheres e sim um fenômeno recente de discriminação indireta, considerada pelos efeitos da ruptura da igualdade de trato, não resultando de mera disposição normativa, mas, sim, de efeitos concretos de melhorias de cifras econômicas, e do desenvolvimento social global do Brasil.

\section{Necessidade e modo de proteção jurídica quanto à igualdade de gênero no modelo constitucional brasileiro.}

Embora a Constituição pátria reclame a igualdade de gênero em todos os níveis , os dłădos a levar em consideração quanto ao tema mercado laboral sinalizam que nos últimos anos apesar de que o setor de serviços seja o mais influenciado pelo crescimento do trabalho feminino, é no âmbito da Administração pública nos níveis federal, estadual e municipal, o maior percentual de servidoras públicas, tendo alcançado uma presença média de $44 \%$, nos últimos cinco anos, segundo dados estatísticos pesquisados inicialmente pelo Ministério de Administração (MARE), dentro do Programa Nacional de Igualdade de Oportunidades na função pública.

Enquanto isso, as mulheres enfrentam grandes dificuldades para assumir cargos de chefia e de responsabilidade no setor público, na mesma proporção da ascensão às funções no desempenho de empregos na iniciativa privada. O que prevalece para o acesso aos cargos públicos é o concurso público, por exigência do art. 37, da Constituição Federal de 1988, entretanto a nomeação à progressão funcional é, em geral, por mérito, prevalecendo, portanto, a maior representatividade de homens como autoridades públicas.

No universo dos cargos em confiança a participação feminina é muito inferior ao número de ingressos por concurso. Nas mais altas funções públicas federais somente 18 mulheres, ou seja, $13,24 \%$ exerciam cargos de chefia, no ano de 1998 , enquanto em 2011 , eram cerca de $20 \%$, da

\footnotetext{
${ }^{9}$ Segundo estatísticas do Instituto de Pesquisa Econômica aplicada (Ipea), na metade das famílias com filhos, as mulheres são as que digirem os lares. Em 53\% das famílias pobres elas são a cabeça de família, enquanto somente 23,7\% das família com filhos são dirigidas por homens. Os dados do IPEA esclarecem que quando a mulher è a chefe de família, è maior a possibilidade de estar em condição de pobreza, inclusive porque a razão da pobreza feminina está associada à divisão não equilibrada da força de trabalho, inclusive porque elas ocupam os postos de mais baixa remuneração.

${ }^{10}$ Gonçalves lembra que no texto institucional brasileiro, tornou-se muito difícil aadequacao da estabilidade constituvional e mesmo sua supremacia no interior do ordenamento jurídico brasileiro, quando, historicamente a sociedae do Brasil desde o império foi extremamente preconceituosa sobretudo porque se ostentavam família partriarcais, trabalho escravo e altos índices de pobreza e analfabetismo. COSTA GONÇALVES, Clàudia Maria. Direitos Fundamentais Sociais. Releitura de uma Constituicao Digirente. Juruá Editora. Curitiba. 2006. Pg. 89.
} 
totalidade dos cargos de chefia do executivo federal, acréscimo também proporcional ao aumento do número de cargos e de ministérios nos governos de Lula da Silva (2007) e de Dilma Rousseff (2010).

Em resumo, quanto maior é o poder de decisão, seja no âmbito público como privado, menor é a participação feminina, sobretudo das mulheres negras. Desse universo perto de $80 \%$ dos cargos de comissão mais inferiores são assumidos por mulheres brancas.

No ano de 2011, somente na Administração pública, 63,2\% dos cargos eram ocupados por mulheres, enquanto que estão nas atividades vinculadas ao setor de serviços, comércio e de limpeza, um alto índice de mulheres. Elas ocupam 94,5\% dos empregos registrados. Portanto, a contratação através de concurso sinaliza uma discriminação positiva, e favorece o acesso das mulheres ao mercado de trabalho, embora seja por mérito e não por força de políticas públicas de quotas.

Quanto ao rendimento médio, os dados oficiais demonstram que os salários das mulheres é, em geral, pelo menos 30\% inferior ao dos varões. São cerca de $\mathrm{R} \$ 786,00$ (setecentos e oitenta e seis reales) cobrados pelas mulheres trabalhadoras brasileiras, enquanto os homens alcançam $\mathrm{R} \$ 1.105,00^{11}$, ou seja, embora as mulheres, em geral tenham um maior tempo de escolarização, ocupam os mais inferiores postos de trabalho e cobram menos, quando comparados ao mesmo cargo ocupado pelos homens.

Si bem que na maioria das atividades econômicas as mulheres são menos remuneradas que os homens. É possível se afirmar que houve uma evolução nos rendimentos mensais dos brasileiros em geral nos últimos dez anos, mais homens e mulheres entraram no mercado laboral pela criação de mais postos de trabalho em virtude do desenvolvimento da economia do país. Assim, nos últimos 20 anos houve uma sensível diminuição das diferenças nos salários médios entre os dois gêneros.

\section{A questão de gênero na pandemia do COVID-19}

No primeiro trimestre do ano de 2020 o mundo começou a sentir os efeitos sanitários, sociais e econômicos da epidemia global proporcionada pela disseminação do vírus COVID-19. A partir da China, todos os países, inclusive o Brasil, sofreram consequências que afetaram, de maneira profunda, a estrutura social, ocasionando prejuízos profundos para o setor público e para o conjunto de relações produtivas, incluindo as laborais. A sociedade de consumo foi afetada de modo definitivo, e quase irreversível, e em sua quase totalidade, pela decretação do estado de emergência em muitos países, com a decretação de fechamento forçado dos setores primários, terciários e de serviços, exigindo, quando possível, a adaptação para o tele trabalho desde quando,

\footnotetext{
${ }^{11}$ Pesquisa Nacional de Amostra Domiciliar (Pnad 2009, do Instituto Brasileiro de Geografia e Estatística-IBGE)
} 
a atividade assim o permitisse.

As diversas incidências no mercado laboral, e das administrações públicas, também afetaram as mulheres, colocando sob novas perspectivas todas as relações humanas, sociais e institucionais, exigindo medidas de ordem pública e segurança sanitárias e obrigando a um mando único de coordenação de gestão da pandemia - algo que não foi assumido pelo governo federal.

A nova perspectiva regulatória precipitou ao setor privado adaptar-se a um complexo jogo normativo no Brasil, desde março de 2020, com regulamentos às vezes distintos, e em outros contraditórios nas instâncias da União, estados-membros e Municípios, exigindo análise estruturada as atividades e ainda do estado de emergência, com impacto direto com a paralises, ou fechamento por completo, de muitos postos de trabalho.

Segundo relatório da Organização Internacional do Trabalho a maioria dos trabalhadores do mundo, cerca de 93\% (noventa e três por cento) residem em países que aplicam medidas de fechamento de locais, sendo sua maioria nas américas.

A perda de horas de trabalho afetou de modo particular os países em desenvolvimento, com repercussão direta e maior proporção às mulheres que, de muitas maneiras convivem com a desigualdade histórica por questão de gênero.

Nesse sentido, o retrocesso nos avanços do mercado laboral foi o resultado mais marcante no incremento da crise - em múltiplas dimensões- gerada pelo corona vírus já que, a diferença de crises anteriores, nesta, o emprego feminino foi mais afetado que o masculino, levando-se em conta que os setores mais atingidos foram o comércio, serviços, sanitários e sociais, todos em primeira fila, são majoritariamente tarefas realizadas por mulheres. Assim, como as administrações públicas, o mercado de trabalho de modo geral, foram impactadas com a preferência pelo trabalho remoto, com reflexos negativos, sobretudo para a população mais vulnerável, e sem acesso aos meios tecnológicos em razão da brecha digital brasileira.

A pandemia, portanto, comprometeu duplamente o setor informal e de trabalhadores jovens, por vezes com poucos auxílios e quase nenhuma garantia de estabilidade e, de forma desproporcionada em relação às mulheres trabalhadoras .

$\mathrm{Na}$ escala mundial, as mulheres trabalhadoras, da administração pública, como do setor privado, passaram a conjugar a vida laboral com o tele trabalho, focando na dimensão dos estereótipos e papeis de gênero na família e na sociedade, sendo em geral as responsáveis tradicionais às tarefas domésticas associadas ao papel de cuidadoras e no apoio as atividades dos filhos.

\footnotetext{
${ }^{12}$ Segundo a OIT, em relatório elaborado pelo Observatório da OIT : a COVID 19 e o mundo do Trabalho. Quinta ediçao . Estimaçoes atualizada e analises, de 30 de junho de 2020. https://www.ilo.org/wcmsp5/groups/public/ @dgreports/@dcomm/documents/briefingnote/wcms_749470.pdf em escala mundial quase 510 milhoes de mulheres trabalham $(40 \%)$ desenvolvem suas atividades nos setores mais afastados nos setores mais afetados pela crise, em geral hotelaria, alimentação, comércio, imobiliárias, empresariais, administrativas, nesses setores 36,6\% são homens.
} 
Assim, as dificuldades de conciliação entre o trabalho e a vida privada foram potencializadas quando, de certo modo, desaparece a vida íntima, com o confinamento e a vida intramuros.

\section{Considerações Finais}

Este artigo pretendeu lançar reflexões sobre a igualdade laboral e o discurso de gênero em tempos de pandemia. Ambos, isonomia e gênero, como esquemas integrados na Constituição Federal de 1988, são traduzidos como um tema recente e pouco abordado em trabalhos e pesquisas científicas no Brasil. Por ele se propõe conciliar o compromisso das instituições com a democratização do acesso a melhores condições de trabalho para as mulheres.

Ao mesmo tempo, no Brasil, o tema está fortemente influenciado pela questão da violência de gênero, e, sobretudo, doméstica contra as mulheres, e meninas. Em geral, respondem somente pelo conjunto de políticas públicas estimuladas pelo governo federal que visam prestar auxílio e assistência preferentemente à infância e à mulher gestante, além do que propriamente responder por questões históricas como as distorções salariais, o teto de vidro, ou um debate aberto e científico sobre os direitos reprodutivos, ou a exclusão social sofrida por mulheres mais vulneráveis.

A condição discriminatória de gênero envolvendo o mundo do trabalho não goza de nenhuma política pública efetiva no Brasil, no período pré-pandemia, ou no estado sob o impacto da pandemia do COVID 19.

Por um lado, tais políticas representariam as responsabilidades e o compromisso do Estado em assegurar uma ruptura com os paradigmas históricos de exclusão e discriminação de gênero em direção à maior inclusão, e proteção, das mulheres no mercado de trabalho. Em outro sentido, a previsão normativa de garantias capazes de concretizar medidas visando uma maior equidade social também são formas de fortalecer as democracias atuais.

Neste sentido, uma nova geração de medidas tem sido orientadas na interpretação do legislador infraconstitucional ao programar o texto político das cartas constitucionais, na aplicação de medidas protetivas, sobretudo no ämbito do direito social. Entretanto, nem sempre a previsão de igualdade, como uma idéia-força, e fonte inaugural de um novo regime social, encontra eco nas decisões e estratégias públicas prioritárias, visando contextualizar a igualdade de gênero também como principio fundamental, e garantia de um direito social essencial e presente.

No bojo deste paradigma está a Administração pública brasileira que ao mesmo tempo conforma, dentro do seu regime jurídico, a possibilidade de inclusão de mulheres no mercado de trabalho provocado pelo concurso público, que apazigua as dificuldades, e cria oportunidades de 
ascensão aos cargos públicos, mas que, entretanto, não propõem medidas mais efetivas no sentido de repartir, de modo equilibrado, competências na ascensão para o preenchimento de cargos de liderança e chefatura, dirigidos preferentemente por varões, salvo nas hipóteses de eleições, como em cargos da administração universitária tais como chefias de departamento, coordenadoria de cursos, reitoras, etc.

A perspectiva de gênero é essencial na análise sob os impactos do COVID-19, nos termos da economia e emprego, como também na crise para esse grupo de sanitários, além dos aspectos da violência intrafamiliar, sendo imprescindível uma resposta eficiente, objetiva e urgente às instituições públicas sobre tais temas.

\section{Referências}

COSTA GONÇALVES, Cláudia Maria. Direitos Fundamentais Sociais. Releitura de uma Constituição Dirigente. Juruá Editora. Curitiba. 2006.

Escola Nacional de Administração Pública (Enap). Gênero, raça e competências de direção no serviço público federal. Cadernos Enap, Brasília, n. 36, 2006.

Escola Nacional de Administração Pública (Enap). Enap Estudos, Servidores Públicos Federais - Gênero. Brasília: Enap, 2014.

GONZÁleZ BUSTOS, M. Ángeles. Medidas Jurídico-administrativas para la protección de la mujer. Estudios multidiciplinares de género. Revista Centro Estudios de la Mujer. N. 3. Aquilafuente. 99. Ediciones Universidad de Salamanca. 2006. Salamanca.

MARTINEZ QUINTEIRO, M. Ester. Discuros y contradiscuros. Las relaciones de Género en el cine. In: Mujeres en la Historia,el arte y el cine: Discursos de Género, Variantes deontenidos y soportes de la Palabra al audiovisual. Aquilafuente. Ediciones Universidad Salamanca. 2011.

PALOMAR OLDEMA, A. El principio de igualdad y La interdicción de la discriminación por razón de seco desde una perspectiva constitucional. In: El tratamiento de género en el ordenamiento español (una visión multidisciplinar de la mujer en los distintos ámbitos sociales). Palomar Olmeda (Coord.) Tirant lo Blanch. Valencia.2005

PNAD, 2009, del Instituto Brasileiro de Geografia e Estatística - IBGE https://www.ipea.gov.br/sites/000/2/publicacoes/bpsociais/bps_16/14igualdade_de_genero.pdf.

SERRA CRISTÓBAL, R., La discriminación indirecta por razón de sexo. Discriminación versus diferenciación (especial referencia a La problemática de la mujer). Ridaura Martines, M. J. Aznar Gómez, M.J. (coord.) Tirant lo Blanch alternativa. Valencia. 2004.

OBSERVATÓRIO DA OIT: COVID 19 e o mundo do Trabalho. Quinta edição. Estimações atualizadas e analises, de 30 de junho de 2020. https://www.ilo.org/ wcmsp5/groups/public/@dgreports/@dcomm/documents/briefing/wcms_749470.pdf. 